\title{
A Psicologia Escolar nas escolas de Boa Vista (RR): concepções dos professores
}

\author{
Soraya Ivon Ramirez Moreno'; https://orcid.org/0000-0003-0651-3504 \\ Gleidson Diego Lopes Loureto2; https://orcid.org/0000-0002-0889-6097
}

\begin{abstract}
Resumo
Este estudo objetivou investigar as concepções dos professores acerca das possibilidades de atuação da Psicologia Escolar (PE) nas escolas públicas de Boa Vista (RR) e verificar as demandas presentes neste contexto. Participaram 131 professores com idade média de 42,6 anos (DP $=7,53)$, sendo a maioria do sexo feminino $(65,6 \%)$. Estes responderam a uma pergunta aberta única e questões demográficas. Verificou-se que a atuação da PE foi concebida tanto no âmbito do modelo clínico, quanto em uma perspectiva mais ampla da escola, convergindo para o denominado modelo sistêmico. Ademais, os dados reforçaram a necessidade de inserção da PE na escola e indicaram demandas emergentes reivindicadas pelo atual cenário da educação brasileira. Apesar dos avanços identificados, ainda existe um desafio de superação da visão clínica da atuação da PE, através de práticas profissionais menos excludentes e posições críticas sobre a realidade escolar.
\end{abstract}

Palavras-chave: Psicologia escolar; professores; escolas públicas.

\section{School Psychology in the schools of Boa Vista (RR): teachers' conceptions}

\begin{abstract}
This study aimed to investigate teachers' conceptions about the possibilities of School Psychology (PE) in public schools in Boa Vista (RR) and to verify the demands in this context. There were 131 teachers with a mean age of 42.6 years $(S D=7.53)$, the majority being female $(65.6 \%)$. These answered a single open-ended question and demographic questions. It has verified that the performance of the EP has conceived both within the clinical model and in a broader perspective of the school, converging to the so-called systemic model. In addition, the data reinforced the need of insertion of the EP in the school and indicated the emergent demands demanded by the current scenario of the Brazilian education. Despite the identified advances, there is still a challenge of overcoming the clinical vision of the work of the EP, through less exclusive professional practices and critical positions on the school reality.
\end{abstract}

Keywords: School psychology; teachers; public schools.

\section{La Psicología Escolar en las escuelas de Boa Vista (RR): concepciones de los profesores}

\section{Resumen}

En este estudio se tuvo por objetivo investigar las concepciones de los profesores acerca de las posibilidades de actuación de la Psicología Escolar (PE) en las escuelas públicas de Boa Vista (RR) y verificar las demandas presentes en este contexto. Participaron 131 profesores con un promedio de edad de 42,6 años (DP = 7,53), siendo la mayoría do sexo femenino (el 65,6\%). Estos respondieron a una pregunta abierta única y cuestiones demográficas. Se verificó que la actuación de la PE fue concebida tanto en el ámbito del modelo clínico, como en una perspectiva más amplia de la escuela, convergiendo para el denominado modelo sistémico. Además, los datos reforzaron la necesidad de inserción de la PE en la escuela e indicaron demandas emergentes reivindicadas por el actual escenario de la educación brasileña. A pesar de los avances identificados, aún hay un reto de superación de la visión clínica de la actuación de la PE, por intermedio de prácticas profesionales menos excluyentes y posiciones críticas sobre la realidad escolar.

Palabras clave: Psicología escolar; profesores; escuelas públicas.

1 Universidade Federal de Roraima - Boa Vista - RR - Brasil; soraya.ramirez@ufrr.com

2 Universidade Federal da Paraíba - João Pessoa - PB - Brasil; diego_loureto@hotmail.com 


\section{Introdução}

No que tange à história da área da Psicologia Escolar (PE), operava-se uma distinção, considerando-a como diferente da Psicologia Educacional. Enquanto esta última era vinculada à prática da pesquisa, a primeira se referia à prática profissional em si (Andrada, 2005). Por outro lado, assevera-se que separar a teoria e prática contribui para um processo de dissociação do exercício profissional da PE, frente ao campo escolar, da base teórica que sustenta tal exercício (Oliveira \& Marinho-Araújo, 2009). Nesse sentido, ambas as nomenclaturas, nessa ocasião, são apreendidas como unívocas e complementares (Bastos \& Pylro, 2016; Dias, Patias, \& Abaid, 2014; Loureto, Moreno, Silva, Santos, \& Xavier, 2015), concebendo a PE como um espaço de produção de conhecimentos, pesquisa e intervenção em relação à esfera escolar/educacional em todas as suas formas de expressões (Marinho-Araújo \& Almeida, 2005), colocando em relevo o compromisso dessa área ou campo de conhecimento com a educação (Barbosa, 2012).

Já em relação à figura dos profissionais da $P E$ no Brasil, muitas das discussões culminam na constatação da ausência, e/ou exclusão sistemática e formal desse profissional no âmbito escolar/educacional. Ademais, em razão de uma série de outros motivos essa área tem passado por dificuldades e contradições (Dias \& cols., 2014). Em termos práticos, a inserção do PE na rede pública de ensino no Brasil constitui ainda uma utopia em função da quantidade de profissionais lotados nas secretarias de educação, bem como pelas suas condições de inserção e atuação efetivas na área. Concretamente existem profissionais contratados por Secretarias Municipais de Educação, mas, por outro lado há um desafio frente ao desenvolvimento do exercício profissional diretamente nos espaços educativos (Guzzo, Mezzalira, \& Moreira, 2012).

Nesse cenário, observamos alguns esforços políticos, no âmbito nacional, com a finalidade de suprir tal lacuna. Ainda no ano de 2000, menciona-se o Projeto de Lei n. 3688, apresentado na mesma data na Câmara dos Deputados, visando garantir o atendimento de profissionais da PE e assistentes sociais em instituições de educação pública básica. Em seguida, após diversas alterações, tal projeto tramitou no Senado Federal, dessa vez, como Projeto de Lei Complementar (PLC) n. 60 de 2007, sendo aprovado nessa instância em 2010 (Dias \& cols., 2014), aguardando até o presente momento sanção presidencial. Ainda, esse projeto desde o seu princípio, ao estipular a prestação de serviços dos campos da psicologia e assistência social não prevê a obrigatoriedade desses profissionais, expressamente, no quadro de funcionários das escolas (Dias \& cols., 2014). Essa situação torna ainda mais difícil a inserção da psicologia no ambiente escolar, sobretudo, pelo fato de que inclusive na Lei de Diretrizes e Bases da Educação Nacional (LDB, 1996), a psicologia constitui excedente não obrigatório ao funcionamento da escola (Campos \& Jucá, 2010).

Por outro lado, em relação ao contexto da cidade de Boa Vista, Roraima, foco do presente estudo, existem três leis estaduais em vigor que dispõem sobre o PE em instituições escolares nesse território. Cronologicamente, a primeira lei, n. 637, é datada de 2008, autorizando o governo do Estado a criar o Programa de Assistência Psicológica a Crianças e Adolescentes nas Escolas Estaduais. Em seguida, no ano de 2013, aprovou-se a lei n. 940 que dispõe sobre a instituição do Programa de Atendimento Psicopedagógico e Social no Sistema Estadual de Ensino Público. Por fim, a lei n. 959 aprovada em 2014 torna obrigatória a aplicação de teste vocacional aos alunos do ensino médio das escolas da rede pública e particular, no âmbito do Estado de Roraima. Entretanto, tais legislações permitem que os profissionais sejam admitidos, também, através de recrutamento, convênios, ou melhor, processo seletivo simplificado. Por fim, até o presente momento nenhum concurso público foi realizado para fins de cumprimentos de quaisquer legislações. Ademais, na esfera municipal não há leis que disponham sobre tal matéria.

A despeito das dificuldades de inserção dos profissionais da PE de modo formal nas escolas do Brasil, alguns esforços podem ser identificados na literatura nacional que buscam mapear a prática da PE dentro do sistema de educação das cidades brasileiras. Por exemplo, no que tange aos estudos realizados em amostras com estes profissionais, em Assis/SP, Cunha e Betini (2003), verificaram práticas psicológicas compartilhadas (foco de intervenção nos contextos escolar e social) e tradicionais, sendo essas últimas de igual modo predominantes em um estudo realizado na cidade de Uberlândia/MG (Souza, Ribeiro, \& Silva, 2011). Já em Campina Grande/PB, Medeiros e Aquino (2011) identificaram que as práticas dos profissionais desarticulavam a teoria e prática, criando uma lacuna entre o que os sujeitos relatam como sendo seu papel e a sua atividade profissional. Em João Pessoa/PB (Aquino, Lins, Cavalcante, \& Gomes, 2015), embora os relatos tenham apontado para atividades de projetos e oficinas, trabalhos junto à equipe pedagógica, dentre outras, os profissionais da PE entrevistados, expuseram um referencial teórico de atuação eminentemente clínico.

Já em relação aos estudos que envolveram os profissionais da educação em geral frente à PE, em Londrina/ PR, Pandolfi e cols. (1999) verificaram que os profissionais da educação entrevistados possuíam uma visão imprecisa do papel da PE. Em Vitória/ES, Rossetti, Silva, Batista, Stein e Hulle (2004) identificaram que profissionais da educação apreendiam o trabalho da PE como uma prática clínica. Em Fortaleza/CE, Miranda, Lima, Teixeira, Chaves e Barros (2007) constataram que as expectativas dos profissionais da educação, majoritariamente, pautavam-se em atendimentos de natureza clínica com enfoques restritos e atuações descontextualizadas. Por fim, em uma capital do sul do Brasil, Prudêncio, Gesser, Oltramari e Cord (2015), identificaram três expectativas de atuação desse profissional: resolução de conflitos entre a família, diagnóstico e no atendimento individual dos "alunos-problema" e prevenção e promoção de saúde.

Por outro lado, há investigações, no cenário nacional, sobre a PE no espaço escolar com amostras exclusivamente de professores. Giongo e Oliveira-Menegotto (2010) realiza- 
ram um estudo com 44 professores em escolas municipais da região metropolitana de Porto Alegre/RS. Os resultados revelaram visões equivocadas acerca da concepção do papel do PE, prevalecendo uma acepção clínica e de que esse profissional apresenta soluções "mágicas" para os problemas. Já em Vitória/ES, o estudo de Bastos e Pylro (2016) contou com uma amostra de 49 professores de um Centro Municipal de Educação Infantil e de uma Escola Municipal de Ensino Fundamental. Verificou-se que os professores apontaram que a atuação da PE volta-se, sobretudo para o aluno "problema" e sua família, o que sugere uma tendência em entender problemáticas, como o fracasso escolar, como tendo origens nesses dois elementos.

Especificamente na região Norte do Brasil, são escassos os estudos, publicados em bases de dados indexadas no campo da psicologia, que abordam em alguma medida o campo da PE. O primeiro estudo trata das contribuições do PE frente aos alunos com necessidades especiais na visão dos professores, na cidade de Boa Vista/RR (Loureto \& cols., 2015), com indexação na Biblioteca Virtual de Saúde (BVS-Psi). Outro estudo investigou a formação e a atuação de profissionais da $\mathrm{PE}$ da rede de ensino público de Rondônia (Tada, Sápia, \& Lima, 2010),estando indexado no portal de Periódicos Eletrônicos de Psicologia (PePSIC). Tal cenário aponta para a necessidade de pesquisas sobre a PE nessa região com a finalidade de fomentar o seu desenvolvimento, sobretudo, em bases de dados indexadas, permitindo assim a veiculação do conhecimento de forma sistemática, assegurando, ainda, a qualidade de tais produções.

Tendo em vista o panorama acima delineado, assim como diante da inexistência de profissionais da PE nas escolas públicas de Boa Vista-RR, o objetivo desse estudo foi investigar as concepções dos professores acerca das possibilidades de atuação da PE nas escolas públicas de Boa Vista (RR), e verificar a partir das falas dos docentes, as demandas presentes nesse contexto.

\section{Método}

\section{Participantes}

Foram contatados 200 professores da rede pública de ensino do município de Boa Vista - Roraima. Os critérios de inclusão dos participantes foram: ser professor(a) e estar lotado(a) em qualquer nível de ensino, em escolas públicas das redes estadual e/ou municipal da cidade de Boa Vista/ RR. Tendo em vista que ocorreram 69 ausências de respostas, contou-se com a participação de uma amostra de conveniência (não probabilística) de 131 professores. Estes tinham idades variando entre 21 e $65(\mathrm{M}=42,6$; $\mathrm{DP}=7,53)$, sendo $65,6 \%$ do sexo feminino $(N=86)$ e $34,4 \%$ do sexo masculino ( $n=45)$, distribuídos entre os ensinos Infantil $(8,4 \%)$, Fundamental $(66,4 \%)$, Médio $(8,4 \%)$ e de Educação de Jovens e Adultos (2,3\%) e maioria de escolas estaduais $(78,62 \%)$.
Ademais, em relação ao tempo de docência, 71,8\% relatou ter entre 11 e 20 anos de atuação profissional, denotando experiência no exercício da profissão. Por fim, $24,4 \%$ dos professores $(\mathrm{N}=32)$ relataram ter tido contato com o trabalho do PE enquanto $75,6 \%$ dos participantes $(\mathrm{N}=99)$ afirmaram não ter tido contato.

\section{Local}

A pesquisa foi executada em instituições escolares da rede pública de ensino do município de Boa Vista-RR, em que houve consentimento e interesse por parte da gestão e corpo docente em participar do estudo.

\section{Instrumento}

Utilizou-se um questionário elaborado pelos pesquisadores com o intuito de coletar informações relativas às possibilidades de atuação e às demandas para a PE. Na primeira parte, o questionário continha perguntas gerais que visavam coletar dados demográficos tais como sexo e idade, e também foram inseridas perguntas sobre o tempo de docência, e dependência administrativa (estadual ou municipal) a que pertenciam as escolas em que os respondentes trabalhavam. Na segunda parte do questionário constava a seguinte pergunta aberta: Em sua opinião, quais as possibilidades de atuação do Psicólogo Escolar para atender às demandas da escola?

\section{Procedimentos}

Inicialmente, entrou-se em contato os gestores das escolas municipais e estaduais de Boa Vista/RR com a finalidade de solicitar autorização e informar o teor do estudo. Após deferimento, prosseguiu-se com o processo de coleta de dados. A seleção dos participantes foi determinada por critério de conveniência.

Respeitando-se as prerrogativas dispostas na resolução 510/16 do Conselho Nacional de Saúde em relação à regulamentação de pesquisas com seres humanos, todos os participantes foram informados sobre os objetivos da pesquisa e ficaram cientes de que seria garantido o anonimato de suas respostas, e que poderiam declinar de sua participação em qualquer momento. Considerando-se esclarecidos, os professores assinaram o Termo de Consentimento Livre e Esclarecido (TCLE). A presente proposta de pesquisa foi aprovada pelo Comitê de Ética da Universidade Federal de Roraima sob o parecer $n^{\circ} 887.555$.

A coleta de dados ocorreu em momentos diferentes entre os meses de julho e agosto de 2015. Os questionários foram entregues pessoalmente e, em alguns casos os professores permaneciam com os questionários para serem devolvidos em ocasião subsequente. Em certos casos, a aplicação era realizada de forma coletiva com a presença 
dos pesquisadores para sanar quaisquer dúvidas referentes aos itens do instrumento.

\section{Análise dos Dados}

Anteriormente aos procedimentos de análise, os dados foram importados para um editor de texto (Open Office Writer) para a criação das linhas de comando para a questão aberta respondida pelos sujeitos da pesquisa. Cada linha de comando correspondeu às Unidades de Contexto Inicial (UCls), isto é, ao número de respostas/sujeitos para tal questão.

Os dados foram analisados por meio do Software de análises de dados textuais Iramuteq (Interface de $R$ pour analyses Multidimensionnelles de Textes et de Questionnaires; Ratinaud, 2009) que consiste em uma ferramenta gratuita (www.iramuteq.org), ancorada no ambiente estatístico $R$ (www.r-project.org) e na linguagem Python (www.python. org). Dentre as análises quantitativas de dados textuais realizadas por tal software, nessa ocasião, empregou-se a Classificação Hierárquica Descendente (CHD). A CHD classifica os segmentos de texto consoante com seus respectivos vocabulários, com base na frequência e qui-quadrado permitindo a criação de classes de Unidades de Contexto
Elementares (UCEs) com as palavras que apresentam um vocabulário similar entre si e distintos das UCEs das demais classes (Camargo, 2005). Por fim, as classes identificadas foram nomeadas, a partir de suas referências temáticas e, em seguida, discutidas com o referencial teórico.

\section{Resultados e Discussão}

A CHD do Corpus Opinião sobre as possibilidades de atuação do PE nas escolas (Corpus 1) foi formada por 131 Unidades de Contexto Inicial (UCls) que corresponde ao número total de sujeitos/respostas. O corpus foi dividido em 95 UCEs, analisando-se 3.998 palavras com média de 5,09 em termos de ocorrências. Ainda, $72,5 \%$ das UCEs foram consideradas na análise, indicando um percentual adequado de aproveitamento dos dados (Camargo, 2005). O corpus se dividiu em cinco classes de segmentos de textos e foram descritas apenas aquelas palavras cujos escores de qui-quadrado eram iguais ou superiores ao mínimo considerado válido para esta análise $\left(x^{2} \geq 3,84\right)$. As cinco classes foram nomeadas, constituindo-se em eixos de análises para a discussão. Na Figura 1 são indicadas a frequência média de cada palavra seguido do valor do qui-quadrado.

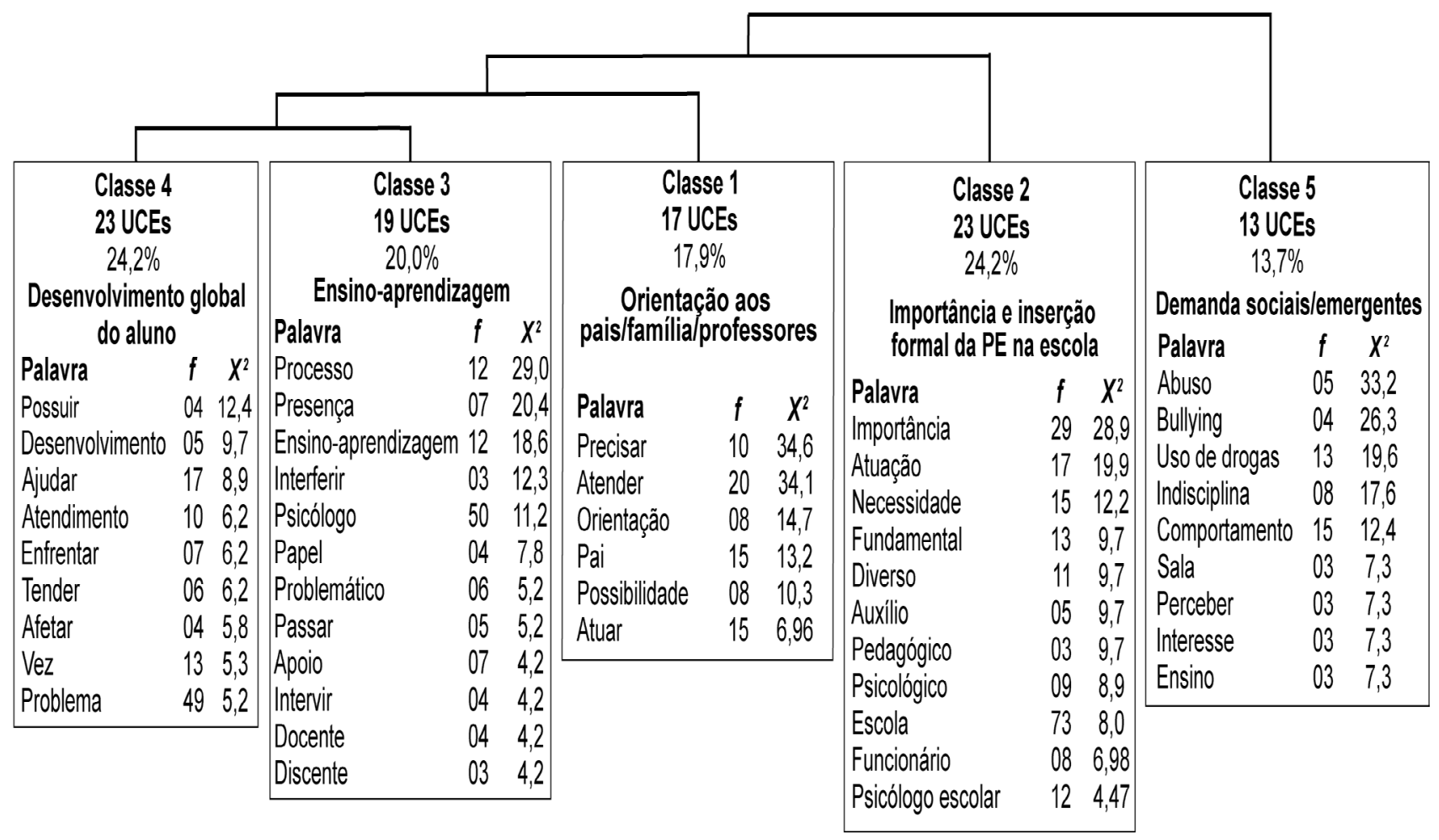

Figura 1. Dendograma da Classificação Hierárquica Descendente do Corpus 1. 
A classe 1, Orientação aos pais/familia/professores, representou $17,9 \%$ das UCEs. Essa classe se relaciona a demandas para a PE voltadas para o atendimento dos professores e dos familiares dos alunos. O excerto ilustra tal demanda: "O psicólogo escolar tem que atender os pais, pois estes precisam de mais ajuda. As crianças são o resultado de pais separados, drogadições, sem educação, maníacos" (Participante 4). Dentre as demandas relacionadas a funcionários e professores foram mencionados problemas de estresse, depressão, conforme menciona o Participante 41 no seguinte excerto: "Extremamente necessária... Muitos professores visivelmente apresentam alguns sintomas de depressão".

Observou-se que a demanda de orientação aos pais/ família/professores é uma possibilidade de atuação ainda fortemente indicada no contexto escolar. O fato de os participantes mencionarem problemas emocionais como alvo de intervenção da PE na escola remete à representação social ainda dominante: a do psicólogo clínico como profissional que "atende", "trata" ou ainda faz "terapia", dado já constatado em outros estudos (Bastos \& Pyrlo, 2016; Miranda \& cols., 2007; Pandolfi \& cols.,1999; Prudêncio \& cols., 2015; Rossetti \& cols., 2004). As demandas e modos de atuação para a PE, aqui elencadas pelos professores podem ter diversas explicações; em alguns casos podem ser resultantes de modelos clínicos terapêuticos de formação ou da atuação dos profissionais inseridos nas escolas (Martinez, 2010; Campos \& Jucá, 2010) mas, também é provável que os professores desconheçam os avanços na $P E$ que levaram a mudanças nas posturas, práticas e abordagens desse campo nas escolas, haja vista que apenas $24,4 \%$ dos professores entrevistados relataram ter tido algum contato como trabalho de profissionais desta área.

A classe 2, Importância e inserção formal da PE na escola $(24,2 \%$ das UCEs), engloba conteúdos que enaltecem a importância da PE para atender a diferentes demandas da escola. Os seguintes recortes textuais ilustram tal classe: "a atuação de psicólogos nas escolas seria de vital importância, implicando em um trabalho de caráter preventivo, tanto para os alunos, quanto para todo o corpo docente, contribuindo significativamente no espaço educacional." (Participante 60). Ao fazer menção à inserção da PE nas escolas, alguns professores destacam a sua ausência no contexto escolar e consideram a presença desses profissionais como um privilégio, conforme menciona o Participante 30 “... nem todas as escolas têm o privilégio de ter um psicólogo, são raras as escolas que têm...”. Ainda, os professores enfatizaram a necessidade de sua inserção formal no âmbito escolar, conforme verificado no excerto: "Esses profissionais são necessários dentro da escola, isso pode acontecer através de concurso público..." (Participante 104).

É relevante a ênfase dos professores sobre a importância da PE nos contextos escolares, indicando que tal atuação é fundamental frente às demandas das escolas, propondo para a PE ações preventivas e interdisciplinares (e.g., com o corpo docente) tendo como foco de intervenção o espaço educacional em si. Propostas de ação desse tipo, também foram verificadas por outros estudos (e.g., Giongo \& Oliveira-Menegotto, 2010; Prudêncio \& cols., 2015). Tais achados denotam avanços acerca da atuação da PE expressas por intervenções menos excludentes e voltadas ao ambiente educacional (Giongo \& Oliveira-Menegotto, 2010). Maluf (2003) já indicava que, em razão da psicologia buscar imprimir uma atuação profissional mais crítica, possibilitou algumas transformações nesse campo, como consequência de movimentos iniciados na área na década de 1980.

Ao destacar a importância da PE nesse contexto, os participantes, de igual modo, mostraram-se favoráveis a uma inserção formal da PE no âmbito escolar por meio de concursos públicos. Em relação à concretização e viabilização da contratação desses profissionais, tal demanda é de fato uma reivindicação justa, pois de acordo com Souza \& cols. (2014) como consequência das críticas às formas de atuação da área da PE em décadas passadas, ocorreu a exclusão sistemática desses profissionais do sistema educacional brasileiro. Guzzo (2008) corrobora a ausência da $\mathrm{PE}$ nas escolas e ainda acrescenta que nas raras exceções em que a inserção da PE ocorre, a mesma é precária. Desse modo, tal cenário ratifica o distanciamento da PE desse espaço específico de atuação.

A Classe 3, Ensino-aprendizagem (20\% das UCEs), tem como centralidade a atuação da PE direcionada aos processos de ensino-aprendizagem dos alunos. O seguinte trecho ilustra essa classe: "É necessário, devido à grande problemática encontrada pelos professores em trabalhar diversos tipos de dificuldades no processo ensino-aprendizagem, uma vez que o psicólogo tem uma metodologia para trabalhar com situações diversas." (Participante 59). Tais demandas elencadas para os processos de ensino aprendizagem são relativas a subsídios e orientações que a PE pode fornecer ao professor, tais como, trabalhos voltados a alunos com deficiências e orientação aos pais dos mesmos, conforme a fala do Participante 19: "Levar os psicólogos a contribuir com os professores na promoção de um conjunto de atitudes que ajudem no trabalho com as crianças com necessidades especiais. Promover ações para desenvolver material adequado para trabalhar com esses alunos".

De fato, a atuação da PE voltada especificamente aos processos de ensino-aprendizagem dos alunos, é uma demanda de atuação considerada tradicional (Martinez, 2010; Rossetti \& cols., 2004), sendo reconhecida por documentos formais que tratam das possibilidades de atuação na PE, tais como a resolução $n^{\circ} 13$ de 2007, do Conselho Federal de Psicologia (CFP), que dispõe sobre os títulos de especialista em Psicologia, indicando que tal profissional pode aplicar conhecimentos psicológicos na escola, referentes ao processo ensino-aprendizagem; e o Manual de Psicologia Escolar/Educacional (Cassins \& cols., 2007) que prevê ações para a compreensão dos processos diferenciados de aprendizagem (aprender a aprender) de cada aluno, bem como auxiliar o professor na articulação entre a teoria de aprendizagem adotada e a prática pedagógica em sala de aula. 
Essas propostas para a PE que pressupõem interlocuções com os professores, se inserem em uma perspectiva crítica de atuação nesta área, pois, de acordo com Oliveira e Marinho-Araújo (2009), o fato do professor ser coparticipante nas atuações frente aos seus alunos, possibilita espaços em que a Psicologia e os docentes reflitam sobre suas práticas e assumam posturas mais críticas diante das queixas escolares, desmistificando as explicações psicologizantes relacionadas às dificuldades de aprendizagem, por exemplo. Por outro lado, a proposta de elaborar materiais e metodologias de ensino, está contemplada dentro de um grupo de propostas de ação também amplas que considera a atuação da PE voltadas a promover a apropriação do conhecimento por todos os alunos (CFP, 2013), ações que abrangem, também, os alunos com necessidade especiais.

A classe 4, Desenvolvimento global do aluno (24,2\% das UCEs), posiciona a PE como um agente facilitador da promoção do desenvolvimento global do aluno, na visão dos professores, conforme o seguinte excerto textual: " $A$ criança no ensino fundamental está passando por frequentes transformações, sejam físicas ou emocionais que no contexto intelectual e social do aluno interferem significativamente no processo de formação. O psicólogo é de extrema relevância para acompanhar o processo" (Participante 70).

A promoção do desenvolvimento global do aluno como atuação do PE foi mencionada pelos respondentes sob a forma de estabelecimento de trocas sociais satisfatórias na escola e na consideração de fatores externos que podem impactar na trajetória do aluno na escola. Tal discurso denota uma visão de atuação da PE correspondente ao modelo pedagógico que, segundo Rocha (1999), contrapõe-se ao modelo clínico por considerar as relações e vínculos que os alunos estabelecem e que impactam no seu aprendizado (Miranda \& cols., 2007). Assim, a PE é convocada a aprofundar e diversificar seus domínios teóricos e práticos para atender essas demandas de atuação sistêmica, superando concepções ambientalistas e inatistas que concebem o desenvolvimento humano como influenciado de forma unidirecional por eventos externos e internos, respectivamente (Soares \& Araújo, 2010).

A classe 5, Demandas sociais/emergentes (13,7\% das UCEs), trata de demandas de atuação voltadas para fenômenos de natureza social que de acordo com as falas dos participantes, interferem, refletem e se expressam diretamente no espaço escolar como ilustra o excerto a seguir: "Na intervenção de casos de indisciplina dos alunos, problemas familiares, homossexualismo na escola, bullying e até mesmo casos de abusos na família que afetam na escola, como também alguns casos de uso de drogas entre outras."(Participante 123). Percebe-se claramente que tais demandas denotam um tipo de intervenção centrada em casos particulares. Novamente, constata-se uma visão clínica de atuação em PE, apontando para um trabalho centrado unicamente no indivíduo, fato que reforça os desafios da expansão do significado do papel da PE frente à comunidade escolar (e.g., ações preventivas; Giongo \& Oliveira-Menegotto, 2010).
Outras demandas foram mencionadas, aqui denominadas como emergentes, pelo fato de serem raramente identificadas nos discursos de professores (Martinez, 2010). Tais demandas propõem elaboração projetos em parceria com professores, realização de palestras envolvendo processos de ensino ou intervenções em campos de ação pouco comuns para os profissionais nesse campo, como por exemplo: “... palestras sobre motivação, autocontrole, psicologia dos desportos, psicologia da aprendizagem" (Participante 88). De fato, as demandas emergentes de acordo com Martinez (2010) são aquelas que apresentam uma nova configuração e que ainda não estão consolidadas ou ainda não têm a mesma visibilidade do que as atuações tradicionais. Um aspecto característico destas demandas é o fato de requerer destes profissionais uma postura flexível e inovadora.

\section{Considerações Finais}

O presente estudo buscou conhecer quais são as possibilidades de atuação da PE no ambiente escolar, na visão dos professores de Boa Vista/RR, além de identificar as demandas para esse contexto. A partir da análise dos dados foram observados cinco eixos temáticos que permitiram identificar as expectativas dos professores relacionadas à área de atuação da PE nas escolas.

Os dados evidenciaram múltiplas concepções sobre a atuação da PE nas escolas, abrangendo problemáticas diversas vinculadas a espaços intra e extraescolares como alvos de intervenção. Em síntese, observou-se que embora algumas possibilidades de atuação identificadas correspondessem a demandas tradicionais atribuídas ao campo de ação da PE, previstas em documentos formais sobre tal especialidade, ainda ratificou-se a necessidade de superar antigos paradigmas da área, fato que impede transformações dos modos de atuação na PE (Maluf \& Cruces, 2008). Por outro lado, foi possível perceber, em alguma medida, visões da PE que remetem a atuações profissionais mais críticas (e.g., interlocução da psicologia com o corpo docente, visão não psicologizante dos alunos etc.) que contribuem para suplantar interpretações deterministas de fenômenos do contexto escolar.

Ademais, observou-se que os professores apontam para a necessidade de inserção informal de profissionais da PE nas instituições escolares. De fato, isso configura um desafio, uma vez que quando concursos públicos são realizados, inúmeras problemáticas são identificadas (e.g., indefinições sobre essa área de atuação, imprecisões nos editais, Guzzo \& cols., 2012; ou admissão via convênios, conforme a legislação em Boa Vista-RR prevê), apontando para a importância de mobilização política por parte desta categoria profissional e articulação com os conselhos regionais e federal.

Ressalta-se ainda que foram identificadas demandas emergentes para a área da PE, cenário que pode ser entendido como produto da sensibilização frente às complexas 
demandas atuais da educação brasileira (Martinez, 2010), questões que merecem a atenção dos profissionais da área. Ressalta-se que estudos (e.g., Maluf \& Cruces, 2008) já assinalavam que a PE passa por uma "nova fase" que é mais facilmente reconhecida nas ações dos profissionais do que nos discursos dos atores do sistema educacional.

Finalmente, apesar das limitações do presente estudo (e.g., amostra não probabilística, impossibilitando generalizações), confia-se que os objetivos tenham sido alcançados, em razão da natureza exploratória ora empreendida. Nesse sentido, apontam-se algumas sugestões de estudos futuro, como por exemplo, investigações envolvendo a percepção de professores de escolas da rede privada de ensino, bem como o acesso a amostras de professores que efetivamente trabalham ou trabalharam com profissionais da PE, obtendo-se, assim, dados pautados em realidades profissionais vivenciadas. Além disso, são convenientes estudos abrangendo os próprios profissionais da área e os discentes, permitindo, futuramente, uma compreensão dinâmica a partir da percepção dos múltiplos atores envolvidos no cenário escolar na referida cidade.

\section{Referências}

Aquino, F. S. B.; Lins, R. P. S.; Cavalcante, L. A.; Gomes, A. R. (2015). Concepções e práticas de psicólogos escolares junto a docentes de escolas públicas. Psicologia Escolar e Educacional, 19(1), 7178.

Andrada, E. G. C. (2005). Novos paradigmas na prática do psicólogo escolar. Psicologia: Reflexão e Crítica, 18(2), 196-199.

Barbosa, D. R. (2012). Contribuições para a construção da historiografia da Psicologia educacional e escolar no Brasil. Psicologia: Ciência e Profissão, 32(spe), 104-123.

Bastos, C. B. R.; Pyrlo, S. C. (2016). Psicologia Escolar na concepção de professores de Educação Infantil e Ensino Fundamental. Psicologia Escolar e Educacional, 20(3), 475-482.

Camargo, B. V. (2005). Alceste: um programa informático de análise quantitativa de dados textuais. In: Moreira, A. S. P. (Org.),Perspectivas teórico-metodológicas em representações sociais (pp. 511-539). João Pessoa: UFPB/Editora Universitária.

Campos, H. R.; Jucá, M. R. B. L. (2010). O psicólogo na escola: avaliação da formação à luz das demandas do mercado. In: Almeida, S. F. C. (Org.), Psicologia escolar: ética e competências na formação e atuação profissional (pp.35-56). São Paulo: Editora Alínea.

Cassins, A. M.; Junior, E. P. P.; Voloschen, F. D.; Conti, J.; Haro, M. E. N.; Escobar, M.; Barbieri, V.; Schmidt, V. (2007). Manual de Psicologia Escolar/Educacional. Conselho Regional de Psicologia - 8a Região. Curitiba: Gráfica e Editora Unificado. Recuperado: 10 fev. 2017. Disponível: http://www.crppr.org.br/download/157.pdf
Conselho Federal de Psicologia (2013). Referências técnicas para Atuação de Psicólogas(os) na Educação Básica. Brasília, DF: autor.

Cunha, B. B. B.; Betini, G. (2003). Psicologia e educação no contexto das secretarias municipais. Psicologia Ciência e Profissão, 23(3), 42-49.

Dias, A. C. G.; Patias, N. D.; Abaid, J. L. W. (2014). Psicologia Escolar e possibilidades na atuação do psicólogo: Algumas reflexões. Psicologia Escolar e Educacional, 18(1), 105-111.

Giongo, C.; Oliveira-Menegotto, L. M. (2010). (Des) Enlaces da psicologia escolar na rede pública de ensino. Psicologia USP, 21(4), 859-874.

Guzzo, R. S. L. (2008). Psicologia em instituições escolares e educativas: apontamentos para um debate. In: Ano da psicologia na educação. Textos geradores (pp. 53-61). Brasília, DF: Conselho Federal de Psicologia.

Guzzo, R. S. L.; Mezzalira, S. C.; Moreira, A. P. G. (2012). Psicólogo na rede pública de educação: embates dentro e fora da própria profissão. Psicologia Escolar e Educacional, 16(2), 329-338.

Lei n. 9.394, de 20 de dezembro de 1996 (1996, 20 de dezembro). Estabelece as Diretrizes e Bases da Educação Nacional. Diário Oficial da União, seção 1. Recuperado: 02 fev.2017. Disponível: http://portal.mec.gov.br/seed/arquivos/pdf/tvescola/leis/lein9394. $p d f$

Lei n. 637, de 18 de janeiro de 2008 (2008, 18 de janeiro). Autoriza o Governo do Estado de Roraima a criar o Programa de Assistência Psicológica a Crianças e Adolescentes nas Escolas Estaduais e dá outras providências. Boa Vista, RR. Recuperado: 02 fev. 2017. Disponível: http://www2.al.rr.leg.br/leis/projetos-e-outrasproposicoes/resolucoes-da-mesa/viewdownload/26-2008/842-lein-637-de-18-de-janeiro-de-2008

Lei n. 940, de 18 de dezembro de 2013 (2013, 18 de dezembro). Dispõe sobre a instituição do Programa de Atendimento Psicopedagógico e Social no Sistema Estadual de Ensino Público, e dá outras providências. Boa Vista, RR. Recuperado: 02 fev. 2017. Disponível:http://www.tjrr.jus.br/legislacao/phocadownload/ leisOrdinarias/2013/Lei-Estadual-940-2013.pdf

Lei n. 959, de 23 de janeiro de 2014. (2014, 23 de janeiro). Dispõe sobre a obrigatoriedade da aplicação de teste vocacional aos alunos do ensino médio das escolas da rede pública e particular, no âmbito do Estado de Roraima, e dá outras providências. Boa Vista, RR. Recuperado: 02 fev. 2017. Disponível: http://www. imprensaoficial.rr.gov.br/diarios/doe-20140123.pdf

Loureto, G. D. L.; Moreno, S. I. R.; Silva, A. C.; Santos, T. B.; Xavier, P. L. O. (2015). Psicologia escolar e necessidades especiais: visão dos professores das escolas de Boa Vista, Roraima. Psicologia Argumento, 33(83), 511-525. 
Maluf, M. R. (2003). Psicologia escolar: novos olhares e o desafio das práticas. In: Almeida, S. F. C. (Org.), Psicologia escolar: ética e competências na formação e atuação profissional (pp. 135-146). São Paulo: Alínea.

Maluf, M. R.; Cruces, A. V. V. (2008). Psicologia educacional na contemporaneidade. Boletim - Academia Paulista de Psicologia, 28(1), 87-99.

Marinho-Araújo, C. M.; Almeida, S. F. C. (2005). Psicologia escolar: construção e consolidação da identidade profissional. São Paulo: Alínea.

Martinez, A. M. (2010). O que pode fazer o psicólogo na escola? Em Aberto, 23(83), 39-56.

Medeiros, L. G.; Aquino, F. S. B. (2011). Atuação do psicólogo escolar na rede pública de ensino: concepções e práticas. Psicologia Argumento, 29(65), 227-236.

Miranda, L. L.; Lima, T. R.; Teixeira, P. A. S.; Chaves, F. L.; Barros, J. P. P. (2007). Perspectivas de atuação do psicólogo escolar na rede pública de ensino: um estudo exploratório em uma escola de Fortaleza. Psicologia da Educação, 25, 113-129.

Oliveira, C. B. E.; Marinho-Araújo, C. M. (2009). Psicologia escolar: cenários atuais. Estudos e Pesquisas em Psicologia, 9(3), 648663.

Pandolfi, C. C.; Ota, A. E.; Strini, G.; Buzolin, I. V. B. O.; Martins, J. B.; Casagrande, L. M. (1999). A Inserção do Psicólogo Escolar na Rede Municipal de Ensino de Londrina - PR. Psicologia: Ciência e Profissão, 19(2), 30-43.

Prudêncio, L. E. V.; Gesser, M.; Oltramari, L. C.; Cord, D. (2015). Expectativas de educadores sobre a atuação do psicólogo escolar: relato de pesquisa. Psicologia Escolar e Educacional, 19(1), 143152.
Ratinaud, P. (2009). IRAMUTEQ: Interface de R pour les Analyses Multidimensionnelles de Textes et de Questionnaires [Computer software]. Recuperado:http://www.iramuteq.org

Resolução $n^{\circ}$ 013/2007 de 14 de setembro de 2007 (2007, 14 de setembro). Institui a Consolidação das Resoluções relativas ao Título Profissional de Especialista em Psicologia e dispõe sobre normas e procedimentos para seu registro. Brasília, DF: Conselho Federal de Psicologia. Recuperado: 02 fev. 2017. Disponível:http:// site.cfp.org.br/wp-content/uploads/2008/08/Resolucao_CFP_ nx_013-2007.pdf

Rocha, M. L. (1999). «A formação na interface psicologia/educação». In: Jacó-Vilela, A. M.; Mancebo, D. (Orgs), Psicologia social: abordagens sócio-históricas e desafios contemporâneos (pp. 183194). Rio de Janeiro, EDUERJ.

Rossetti, C. B.; Silva, C. A.; Batista, G. L.; Stein, L. A.; Hulle, L. O. (2004). Panorama da psicologia escolar na cidade de Vitória: um estudo exploratório. Paidéia, 14(28), 191-195.

Soares, P. G.; Araújo, C. M. M. (2010). Práticas emergentes em Psicologia Escolar: a mediação no desenvolvimento de competências dos educadores sociais. Psicologia Escolar e Educacional, 14(1), 45-54.

Souza, C. S.; Ribeiro, M. J.; Silva, S. M. C. (2011). A atuação do psicólogo escolar na rede particular de ensino. Psicologia Escolar e Educacional, 15(1), 53-61.

Souza, M. P. R.; Ramos, C. J. M.; Lima, C. P.; Barbosa, D. R.; Calado, V. A.; Yamamoto, K. (2014). Atuação do psicólogo na educação: Análise de publicações científicas brasileiras. Psicologia da Educação, 38(1),123-138.

Tada, I. N. C.; Sápia, I. P.; Lima, V. A. A. (2010). Psicologia Escolar em Rondônia: formação e prática. Psicologia Escolar e Educacional, 14(2), 333-340.

(cc) EY License information: This is an open-access article distributed under the terms of the License (type CC-BY), which permits unrestricted use, distribution and reproduction in any medium, provided the original article is properly cited. 